\title{
Application of Discrete Element Methods to the Problem of Rock Bumps
}

\author{
P. P. Procházka, M. G. Kugblenu
}

This paper is a continuation of a previous paper by the authors. Applications of two discrete element methods (DEM) to several fields of geotechnics are discussed. The free hexagon element method is considered a powerful discrete element method, and is widely used in mechanics of granular media. It substitutes the methods for solving continuum problems. In order to complete the study, other discrete element methods are discussed. The second method starts with the classical particle flow code (PFC, which uses dynamic equilibrium), but we apply static equilibrium in our case. The second method is called the static particle flow code (SPFC). The numerical experiences and comparison with experimental results from scaled models are discussed.

Keywords: free hexagonal element method, statical PFC, localized damage, occurrence of cracking and bumps during mining or tunneling.

\section{Introduction}

The arguments for using discrete element methods instead of methods defined on the continuum of the entire domain were discussed in a previous paper by the authors, [9].

In the early 1970s Cundall, [2], introduced discrete, elements starting with dynamic equilibrium. First, brick-like elements were used (professional computer program UDEC), and later circular elements in 2D and spherical elements in 3D (PFC- particle flow code - both computer systems issued by ITASCA) simulated the continuum behavior of structures. Such methods have been applied mainly in geotechnics, where soil is a typical grain material with the above-mentioned shape, [14]. If the material parameters are well chosen, the mechanical behavior of the discrete elements is very close to reality. The problem consists of finding such material parameters. There have been many attempts to find out these parameters, but there is still no satisfactory output from these studies. It seems promising to cover of the domain defining the physical body by hexagonal elements, which are very similar to disks, and can cover the domain with very small geometrical error. The internal mechanical behavior is described by virtue of the boundary element method, e.g. [1]. The shape is probably derived from honeycombs [11].

The examples are taken from the field of geotechnical problems; particularly opening face stability is discussed. Experimental measurements from a scale model are compared with numerical treatments for the occurrence of bumps during tunneling or mining. The reliability of the proposed methods is tested for rock bumps in coalmines. The experimental data and the results from these models are in good agreement, cf. [14]. An application to tunnel face stability can be found in [10]. The extrusion of gas in the coalmine can be described by eigenparameters, [3], or, in this case, Eshelby's trick is used [4].

\section{Rock bumps}

Bumps are a typical problem in mining engineering, but they have not yet been adequately studied. There is a lack of numerical models, which this paper should partly bridge. The examples focus on two basic problems: bumps due to extreme depth of the mine, and the influence of gas emissions.
In the first case, static PFC is also employed and the two numerical methods are compared with the experimental results.

For bumps to occur, the rock has to possess certain particular material properties, leading to an accumulation of energy and the ability to release this energy. Such a material may be brittle, or the bumps may arise at interfacial zones of two parts of the rock that have principally different material properties.

The experiments concentrate on the loading of a longwall seam. The coal is supposed to be drilled at great depths. The mathematical models have been prepared in compliance with the experiments. Both numerical methods, the free hexagonal element method and static PFC are selected to assess the local energy concentration and forthcoming bumps.

First, let us look back and mention certain interesting publications dealing with local sudden failure of stability. Haramy et al [5] studied the behavior of cubes of coal that were loaded by a concentrated load. The tests were made on irregular lumps.

Ujihara et al [13] discuss a scale model and theoretical studies on the mechanism of coal and gas bumps. The authors aimed to establish a comprehensive theory on the mechanism of coal and gas outbursts. They reasoned that an effective method for elucidating the mechanism involves scale model laboratory experiments, because the phenomena can be observed precisely not only with the naked eye but also with appropriate measuring methods. Experimental results and numerical analyses of stresses indicate that the mechanism of coal and gas outbursts is mainly due to gas pressure, rock pressure and sudden face exposure. Gas pressure contributes to fracturing as well as transporting the coal. From both the numerical and the experimental results it follows that there is a typical paraboloidal disconnecting surface, with the principal axis meeting the axis of the tunnel or seam.

In addition, in [8] a model material is used to simulate coalmine bumps. The authors concentrate on the stability of coal seams that are intersected by a straight, infinite cavity, representing a tunnel, a roadway, a gallery, or a longwall working. They observe that a large experimental (and obviously also in situ) scatter of critical pressure, necessary for bump initiation, can be understood as a consequence of the variance of the material. 
Since in situ rock strength needs to be determined for successful design of underground structures, the Bureau of Mines in Denver (there is now only one Bureau of Mines in the USA, located in Pittsburgh) issued a series of publications, where estimates for engineers can be found. A summary is published in [7], where it is pointed out that at failure rocks with a wide range of strengths approximately satisfy the following equation:

$$
\frac{\tau}{\sigma^{+}}=A\left(1-\frac{\sigma}{\sigma^{+}}\right)^{2 \beta},
$$

where $\tau$ and $\sigma$ are the shear and normal stresses along the failure plane, $\sigma^{+}$is the rock tensile strength (note that tension is positive), $2 \beta$ is a universal constant equal to $0.684 \pm$ correctional term, and $A$ is a material constant. Values for $A$ are determined from the triaxial compression test and borehole shear test reported in [7], which are approximately 3.018 , and 2.466, respectively; the values are comparable to $A$ determined using the Hoek and Brown material constants for failure of undisturbed and disturbed rock masses.

Large scale experiments were carried out and the constants for the above-mentioned failure criterion were: $2 \beta=0.684 \pm 0.017, A=2.466 \pm 0.58$ for undisturbed material, and $A=3.018 \pm 0.88$ for disturbed mass.

A strong roof helps to minimize roof fall problems in coalmine entries, see [6]. However, the inability of a strong roof to cave readily may contribute to major ground control problems in longwall and retreat mining operations. Concern expressed by mine operators prompted the authors to analyze the effects of strong roof members on ground stability around longwall openings.

\subsection{Laboratory testing devices}

Fig. 1 is a sketch of the loading cell. It consists of a lower steel tank that is designed for the horizontal forces that are caused by the vertical load in Araldite specimens. The loading cell is equipped with Perspex on its sides, which enables observation of the deformation processes during the tests.

The described loading cell models the rock mass near the face of the opening. In the loading cell, two Araldite specimens are placed (both 160/400/40 $\mathrm{mm}$ ) that model the real tunnel. The gap between them corresponds to the width of a working gallery in a mine.

The mechanism and history of the coal bumps was observed on this Araldite specimen, which was covered by a soft Duralumin sheet with force meters placed on it in the following manner: 5 wider force meters were placed near its outer edge, and another 15 thinner force meters were placed next to them, see Fig. 1. In order to embed the force meters properly and to prevent them from tilting, another double steel sheet, $1 \mathrm{~mm}$ thick, was placed over the force meters. A $300 \mathrm{~mm}$ high block of Duralumin was placed over this sheet. The purpose of this block was to model the hanging wall and to facilitate the stress distribution similarly as in reality.

The sizes of the force meters were: length $160 \mathrm{~mm}$, height $68 \mathrm{~mm}$, width 16 or $32 \mathrm{~mm}$. On each force meter 4 strain gauges were placed, and their distribution enabled us to measure the deformation along its full length. The strain gauges are connected in series in order to be able to gauge each force meter separately, and simultaneously to increase the gauging sensitivity. The force meters were calibrated within the expected range of forces, that is 0 to $250 \mathrm{kPa}$.

In the scale model the concrete was substituted by Dural soft sheet with physically equivalent material properties, according to Buckingham's theorem, see [12]. The scale was approximately $1: 250$, meaning that the opening was $4.75 \mathrm{~m}$ high. This height was also applied in the mathematical models, for comparative studies. For more details, see [14].

Fig. 2 shows the distribution of the vertical stresses along the contact between the upper rock and the lower coal seam

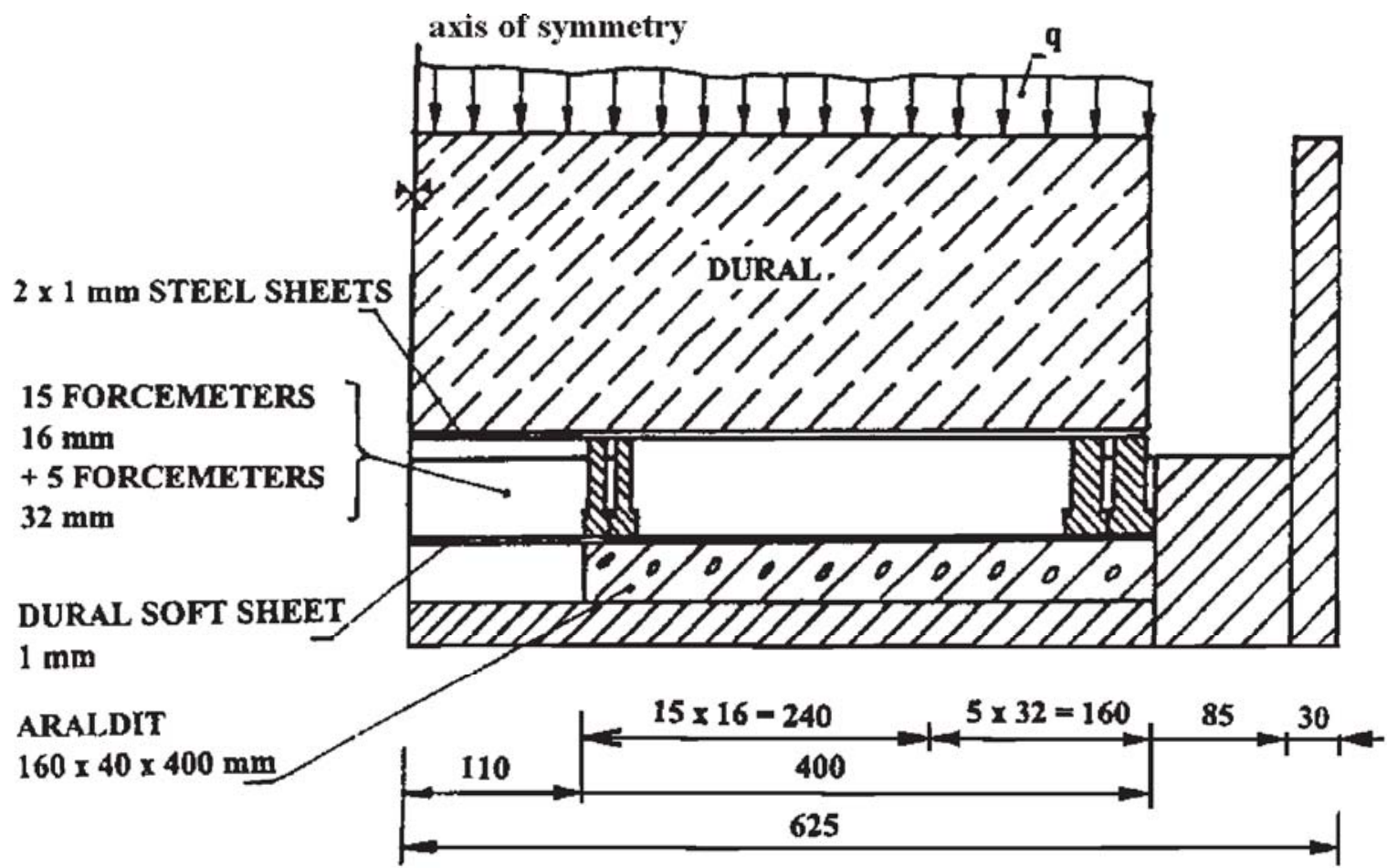

Fig. 1: View of the symmetric part of the specimen 


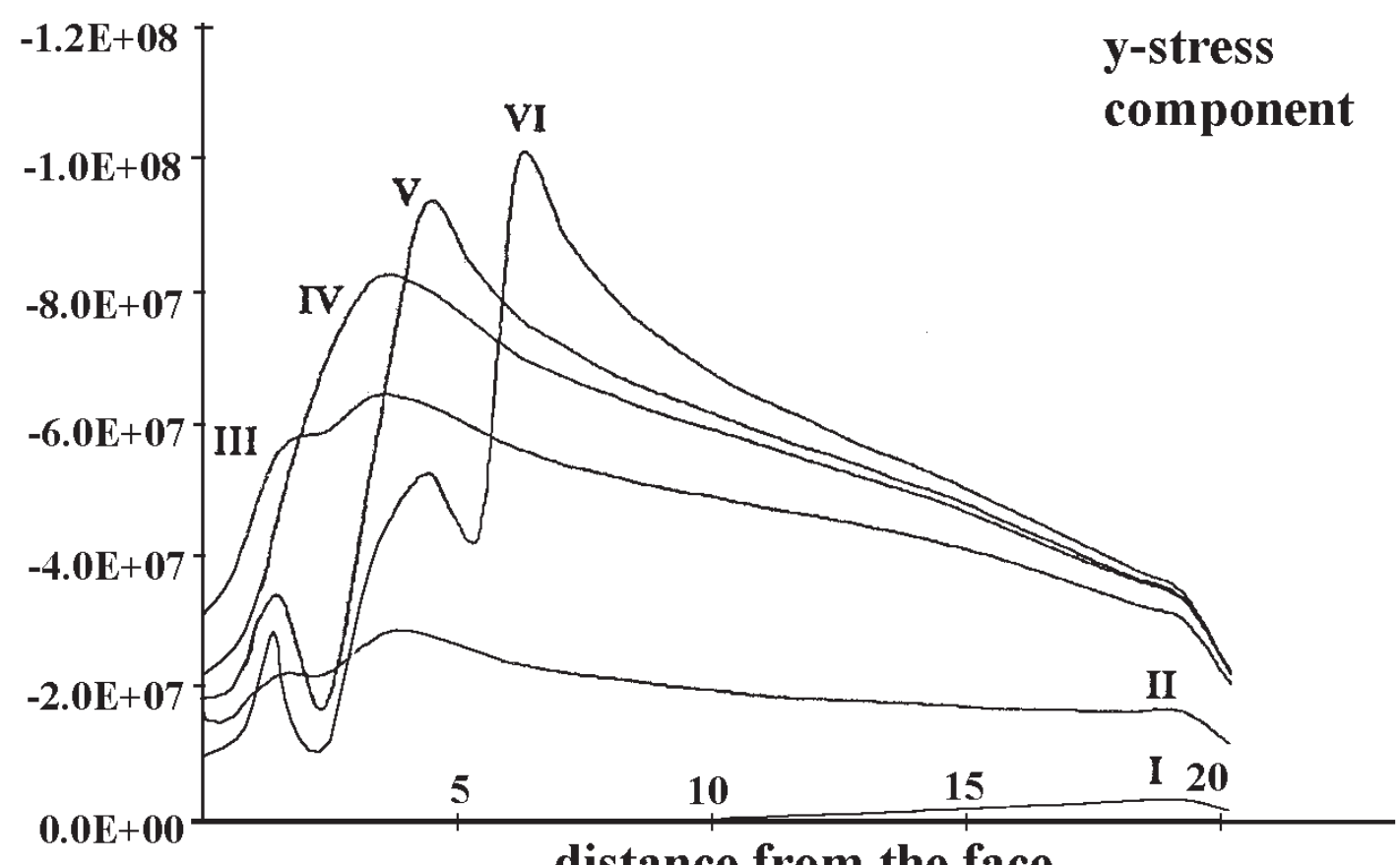

Fig. 2: Distribution of $y$-stresses [MPa] behind the opening.

Loading along the terrain:

I- $1 \mathrm{kPa}$, II- $1 \mathrm{MPa}$, III- 1.5 MPa, IV- $2 \mathrm{MPa}, \mathrm{V}-2.5 \mathrm{MPa}, \mathrm{VI}-3 \mathrm{MPa}$.

in dependence on the distance from the face of the opening for various applied stresses. $S_{\mathrm{ij}}$ denotes the load, which range from 0 to $3 \mathrm{MPa}$. At the value of $2.5 \mathrm{MPa}$, the bumps occurred and the stress in the sides of the opening obviously increased. This is why the value $2.5 \mathrm{MPa}$ of the terrain loading is considered as decisive in the mathematical models.

The experiments were carried out at the Klokner Institute of CTU Prague, [14].

\subsection{Examples}

Fig. 3 shows the mesh of particles in the static PFC with the generalized Mohr-Coulomb friction and cohesion law, and exclusion of tensile stress exceeding the tensile strength, as described in [9]. The internal radius of the hexagonal particles is $0.25 \mathrm{~m}$, and the number of particles is 1532 . The lower part with the free face represents the coal seam, and the upper part is the rock. The coal seam is $4.75 \mathrm{~m}$ high, as in the experimental model.

The numerical procedure for solving the problems is the over-relaxation method, with improvement of the unknowns in the sense of the contact conditions between the adjacent disks. First, the fixed contacts are considered, i.e., high penalty coefficients are introduced. After 1000 iteration steps the contact conditions are taken into account and after approximately another 1500 iteration steps the procedure terminates. The termination obeys the rule of Euclidean norm er-

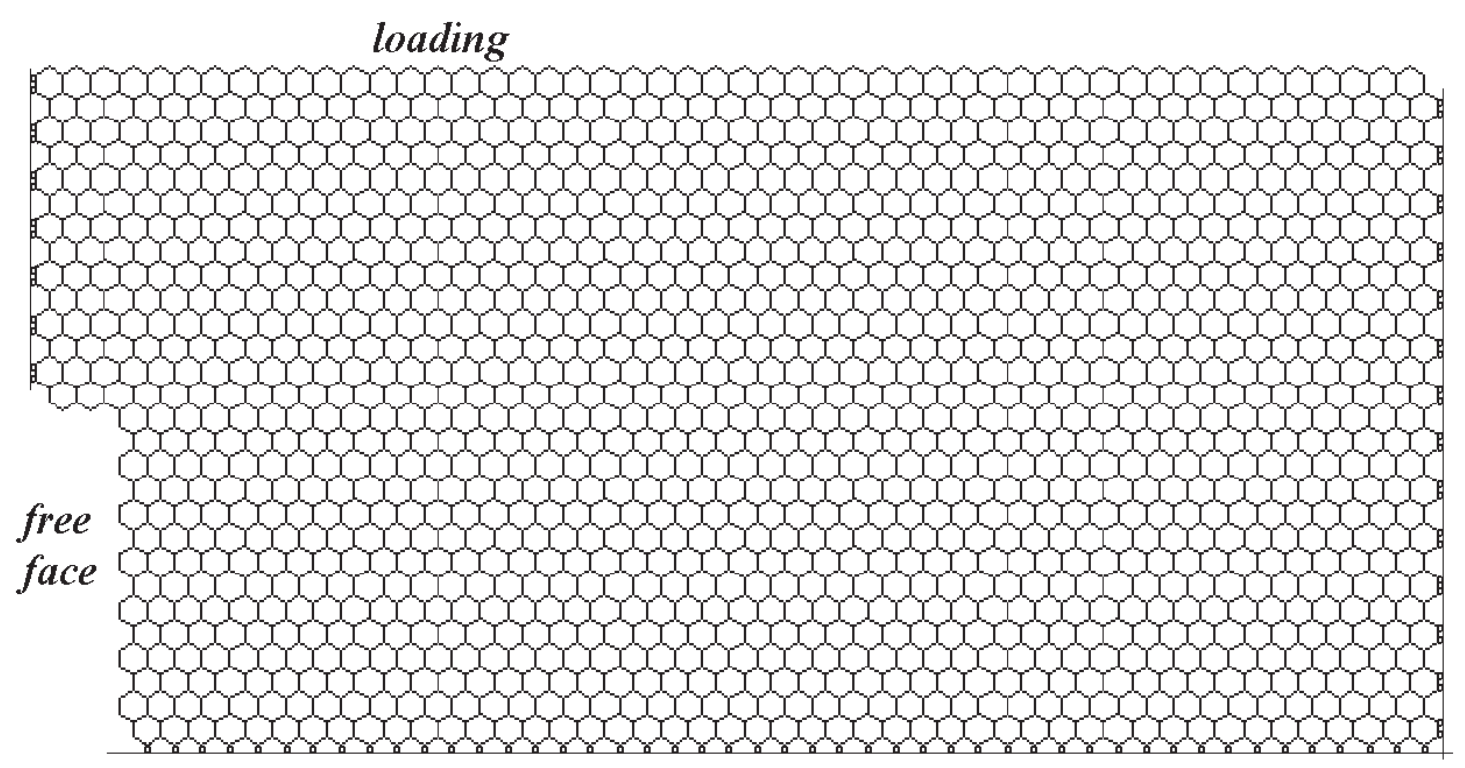

Fig. 3: Setting of the hexagonal elements and boundary conditions 


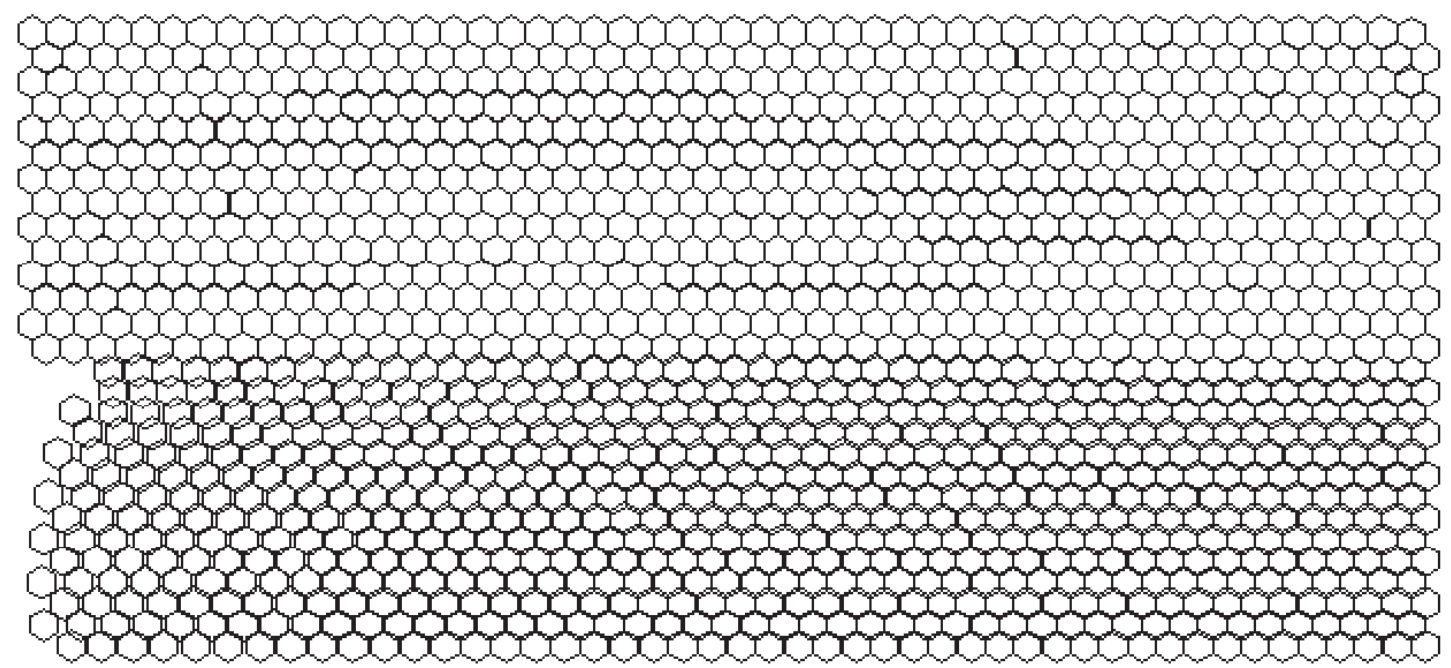

Fig. 4: Movements of particles in an elastic solution

ror imposed on the change of displacements of the centers of the particles. All these values are considered for the examples discussed below.

Note that when using static PFC, the final load is divided into 10 equal increments to suppress the influence of possibly large rotations. Since the elastic-plastic law is applied to the free hexagon solution, the structure is from the beginning loaded by full loading.

Two examples are discussed in this text. First, the opening stability during mining is studied, and the results are compared with the experiments. The results from the hexagonal method and from static PFC are compared, and the experimental measurements are taken into consideration. The second example studies the influence of gas emission on the face stability and is illustrated for two values of pressures, which are located in the coal seam due to gas emission.

Both examples focus on the problem of extrusion of rock (or coal) mass from the rock body. The geometry of the hexagonal elements is shown in Fig. 3, where the boundary conditions are also depicted. This mesh is also used for the disks in such a way that the centers coincide with the hexagons and the radius is also $0.25 \mathrm{~m}$.

The material coefficients in the hexagons are: $E=500 \mathrm{GPa}, G=150 \mathrm{GPa}$, shear strength $c=1 \mathrm{MPa}$ and tensile strength $p_{\mathrm{n}}^{+}=100 \mathrm{kPa}$. These values are valid for the rock. The lower part with the free face describes the coal; its material properties $\mathrm{E}$ and $\mathrm{G}$ are ten times lower than those of the rock, but the shear strength and the tensile strength vary. The load is given by the overburden. The volume weight $\gamma=25 \mathrm{kN} / \mathrm{m}^{3}$, the depth of the opening is $1000 \mathrm{~m}$.

The disks are connected by springs with the following material properties: $k_{\mathrm{n}}^{\mathrm{ij}}=500 \mathrm{GN} / \mathrm{m}$ and $k_{\mathrm{t}}^{\mathrm{ij}}=150 \mathrm{GN} / \mathrm{m}$, shear strength $c=1 \mathrm{MN} / \mathrm{m}$, and the tensile strength $p_{\mathrm{n}}^{+}=100 \mathrm{kN} / \mathrm{m}$ for the rock. For the coal it holds: $k_{\mathrm{n}}^{\mathrm{ij}}=50 \mathrm{GN} / \mathrm{m}$ and $k_{\mathrm{n}}^{\mathrm{ij}}=15 \mathrm{GN} / \mathrm{m}$, the shear strength and the tensile strength change in compliance with the hexagons.

In Fig. 4, the movements of the particles describe the elastic solution. Here and in the other figures, the particles

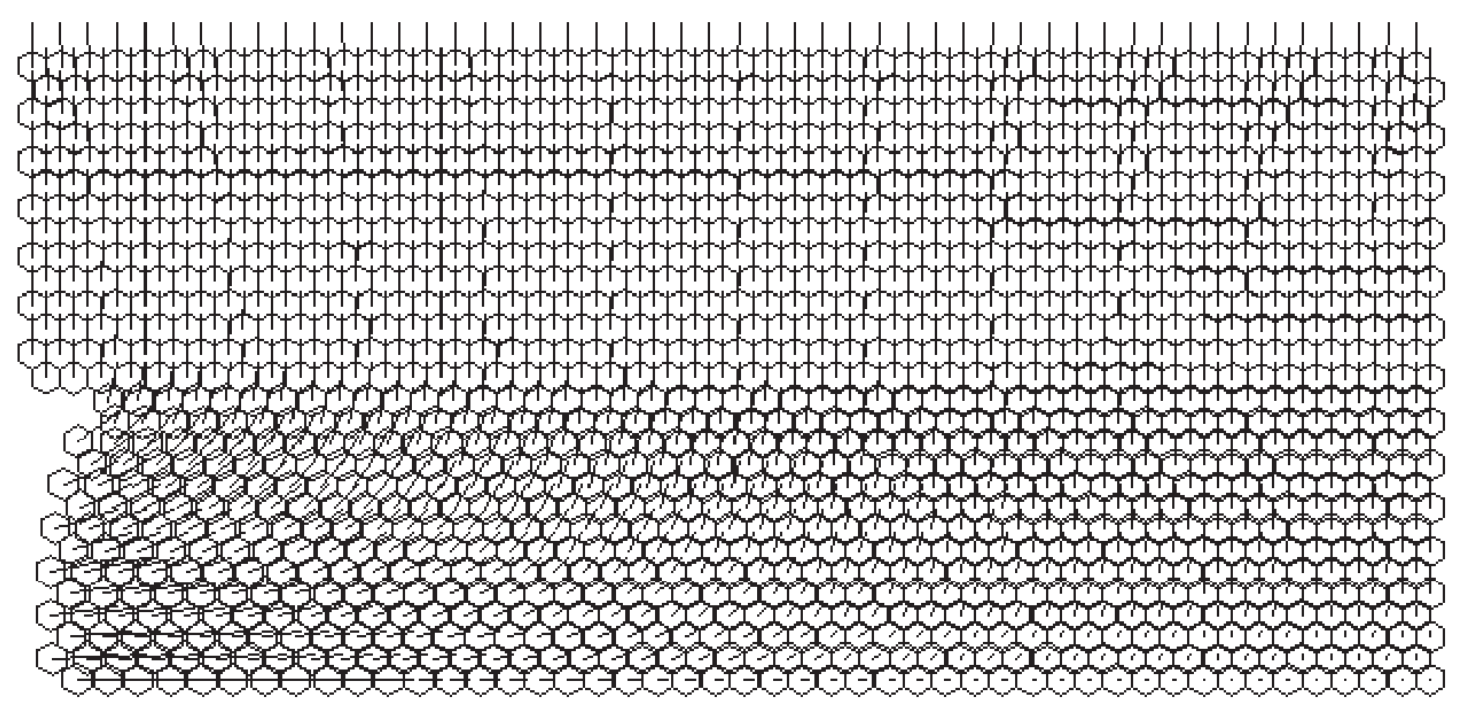

Fig. 5: Movements in an elastic solution with their vectors 


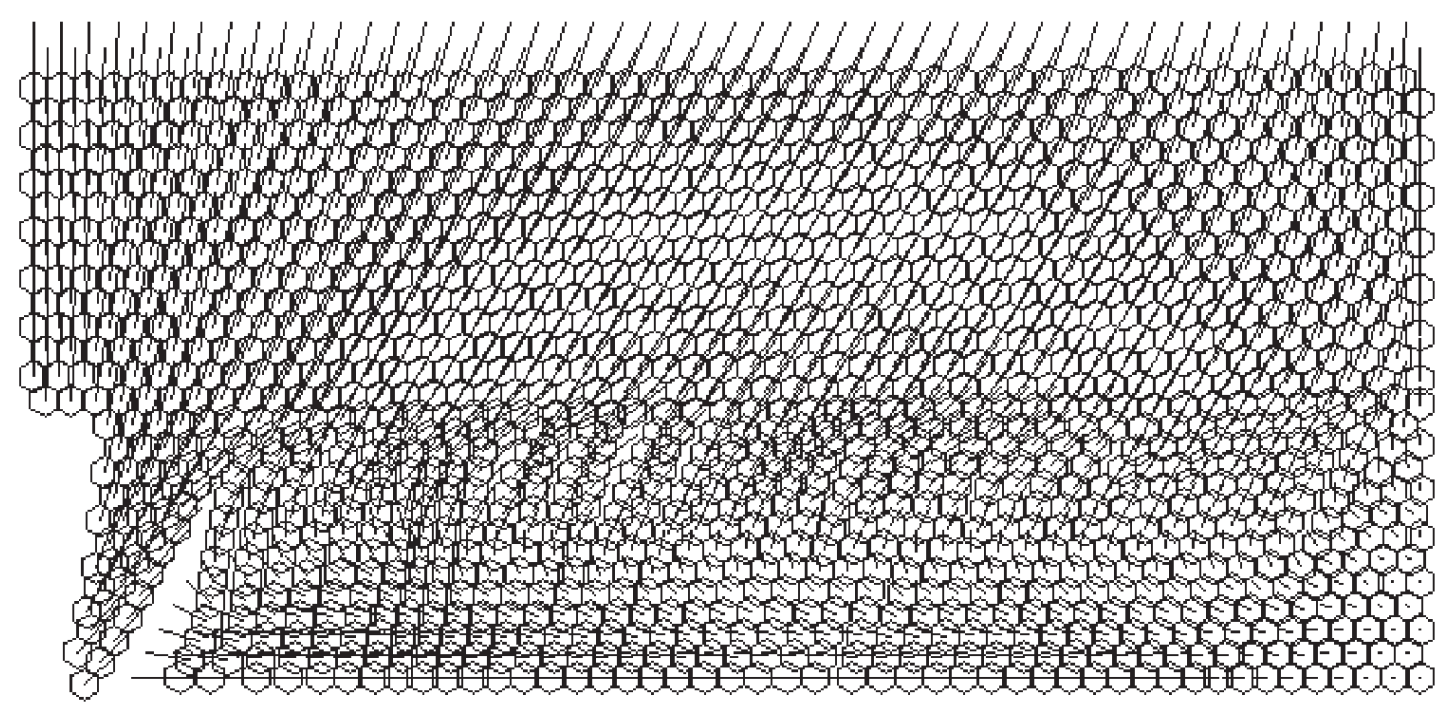

Fig. 6: Movements for $p_{\mathrm{n}}^{+}=10 \mathrm{kPa}, c=150 \mathrm{kPa}$

are drawn as rigid, although they change their shape after deformation.

In Fig. 5, the same movements are depicted with the displacement vectors. The vectors start at the centers of the particles in the undeformed state and end at the centers of the moved elements.

Fig. 6 shows a typical situation. The extrusion of the particles is observed in the front part, while next to the face (approximately $3 \mathrm{~m}$ ) the particles move backwards and stabilize the coal seam. This can change after some other influence, e.g., due to gas emission, as is shown in the following pictures. The movements of the rock and coal with these material properties make the opening stability relatively safe. Some particles at the face of the seam are disconnected, but the direction of the vectors shows the still stabilized influence of the overburden. It should be noted that the nucleation of the crack zones is seen in the right upper part of the rock, which causes a drop in the stresses in this region. Fig. 7 shows the same arrangement of the system discussed in Fig. 6, but in this case static PFC is used. The displacements at the face are principally smaller, but the triangular wedge is created in a similar manner as for the hexagons. As the process of cracking is influenced by the contact conditions rather than by the springs, statical PFC is obviously less reliable than the hexagon method.

The most dangerous case is depicted in Fig. 8 for hexagons and in Fig. 9 for disks. The triangular wedge is disconnected into two parts, and extrusion of particles is now obvious. Similar pictures are shown in Figs. 10 and 11.

It can be proved, that for tensile strength of $3 \mathrm{kPa}$, shear strength higher than $300 \mathrm{kPa}$ does not principally change the movement configuration. A similar conclusion is also valid for other relations $p_{\mathrm{n}}^{+}$and $c$.

A wide range of computations were carried out to get the relation $p_{\mathrm{n}}^{+}$and $c$ at the occurrence of the bumps, which is determined as a singular solution of the problem. The relation is shown in Fig. 12. The numerical results are in reasonable agreement with the experiments carried out at the Klokner Institute of CTU Prague. This conclusion follows from Fig. 13. The deviations on the left hand side of the picture are probably caused by the relatively rough mesh

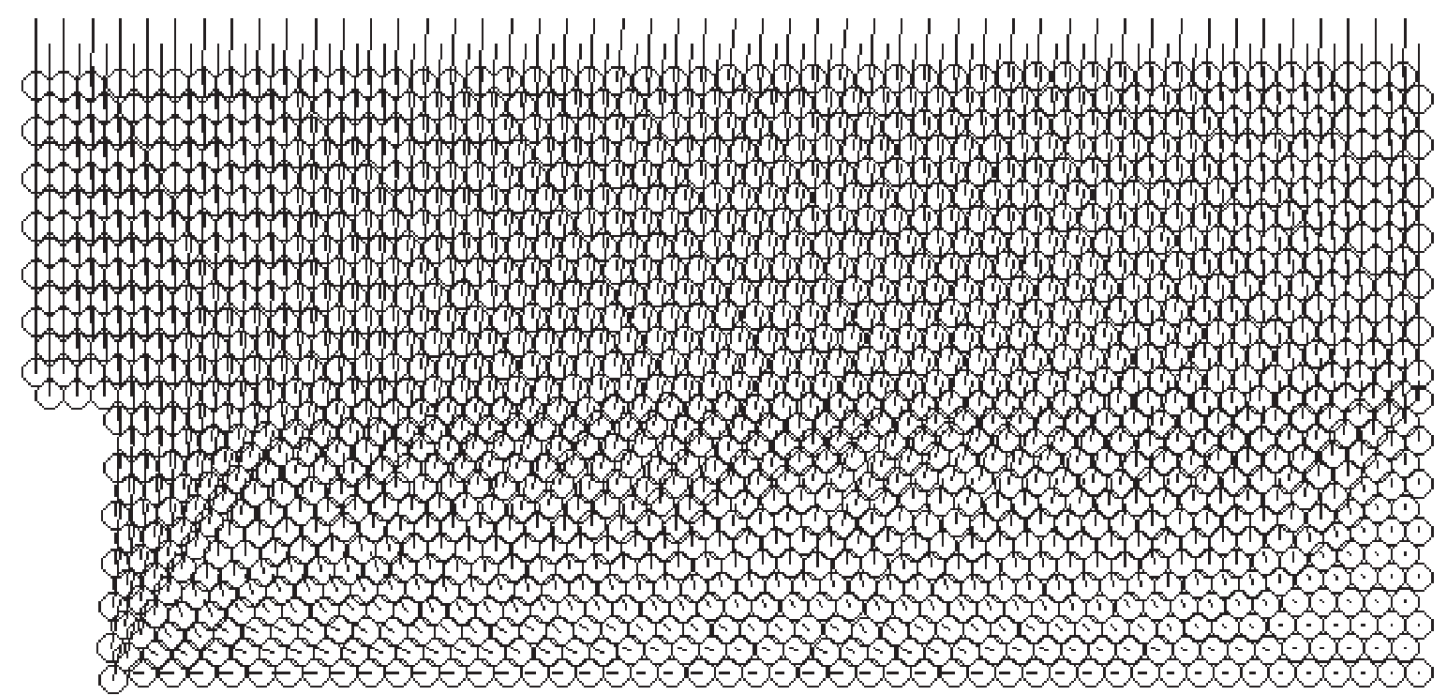

Fig. 7: Movements for $p_{\mathrm{n}}^{+}=10 \mathrm{kPa}, c=150 \mathrm{kPa}$ 


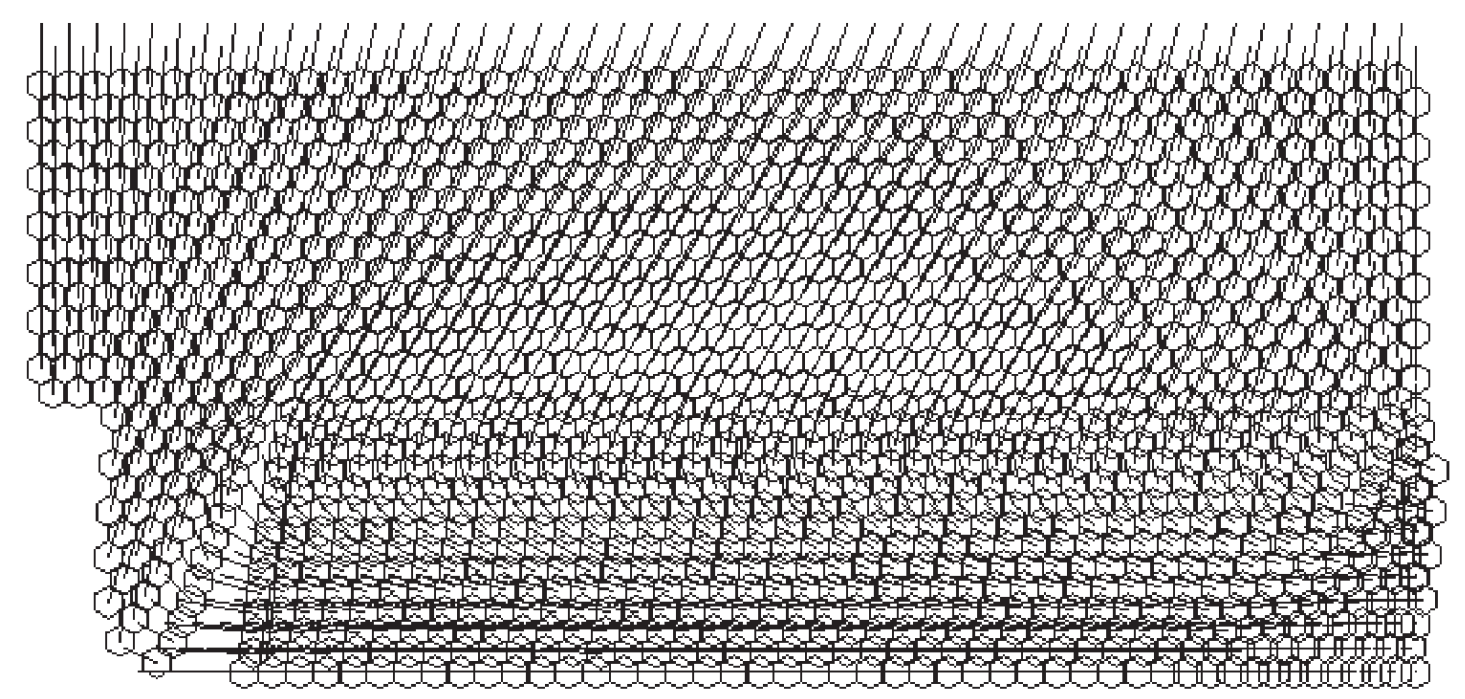

Fig. 8: Movements for $p_{\mathrm{n}}^{+}=5 \mathrm{kPa}, c=150 \mathrm{kPa}$

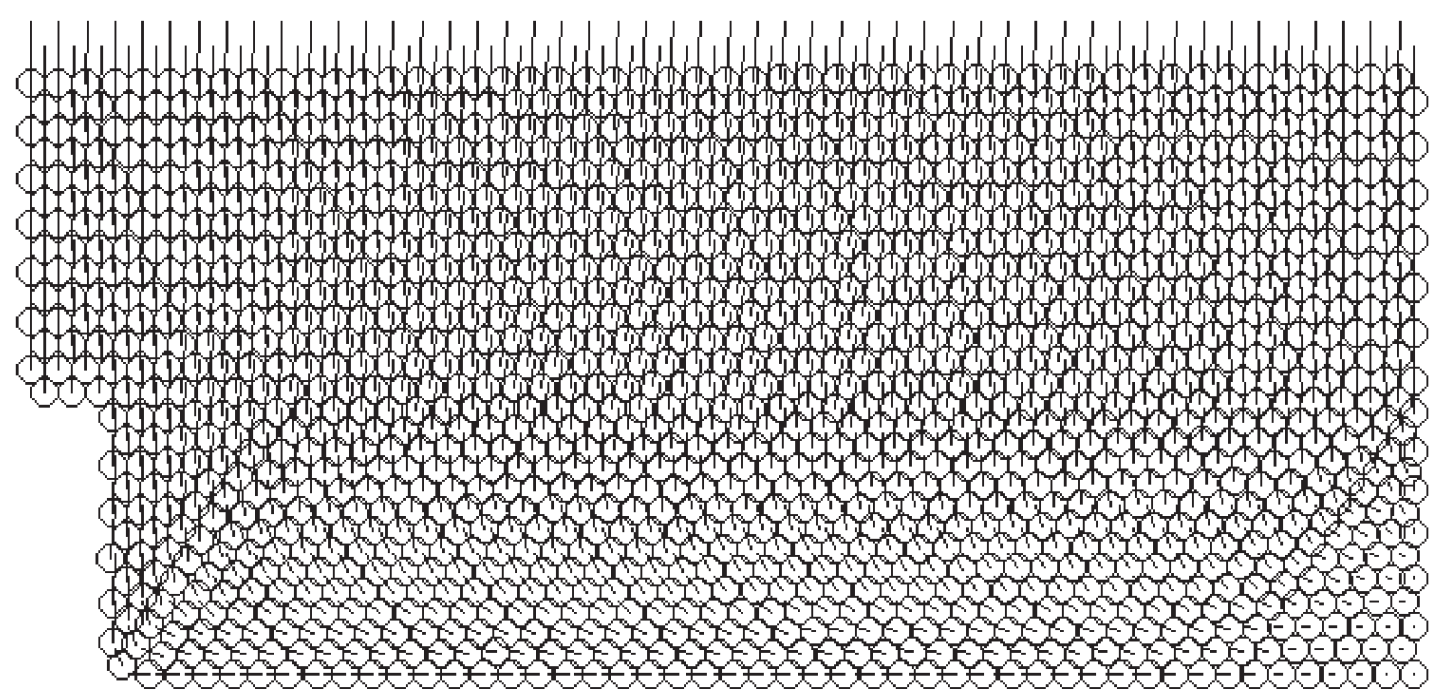

Fig. 9: Movements for $p_{\mathrm{n}}^{+}=5 \mathrm{kPa}, c=150 \mathrm{kPa}$

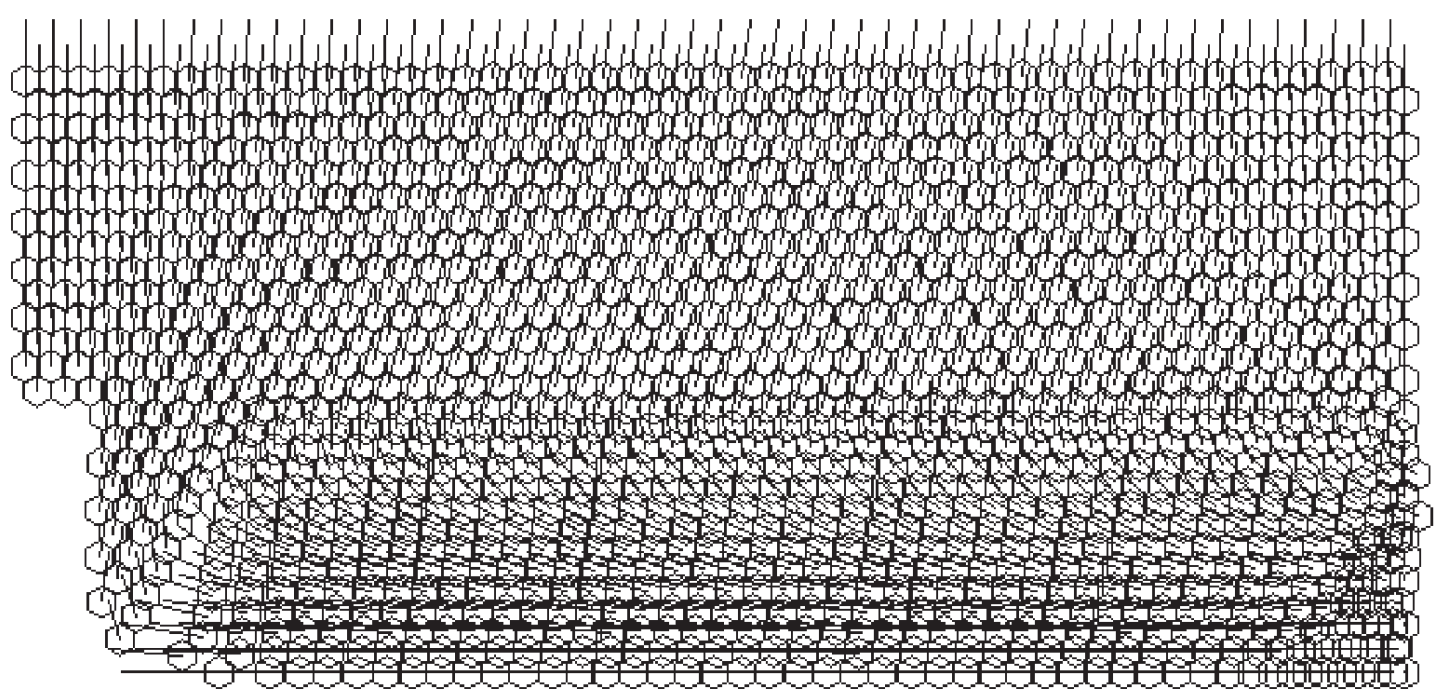

Fig. 10: Movements for $p_{\mathrm{n}}^{+}=10 \mathrm{kPa}, c=150 \mathrm{kPa}$ 


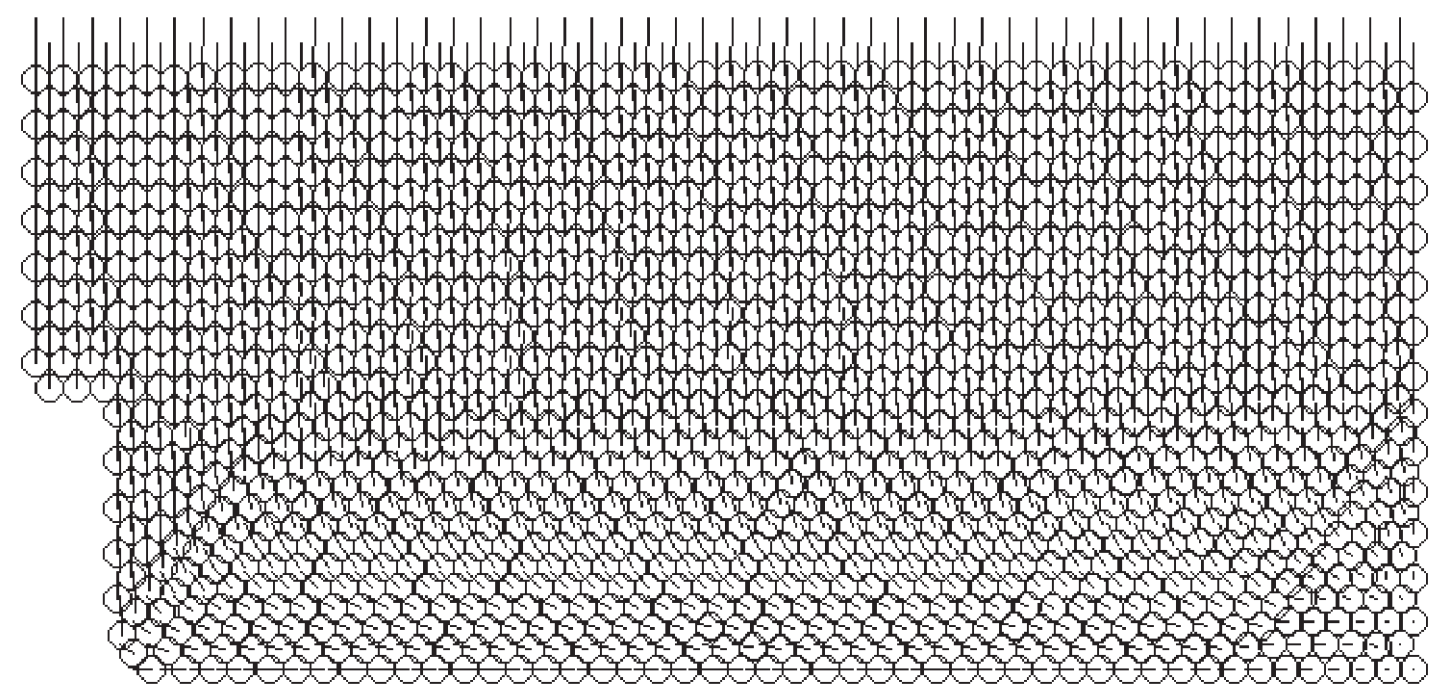

Fig. 11: Movements for $p_{\mathrm{n}}^{+}=3 \mathrm{kPa}, c=300 \mathrm{kPa}$

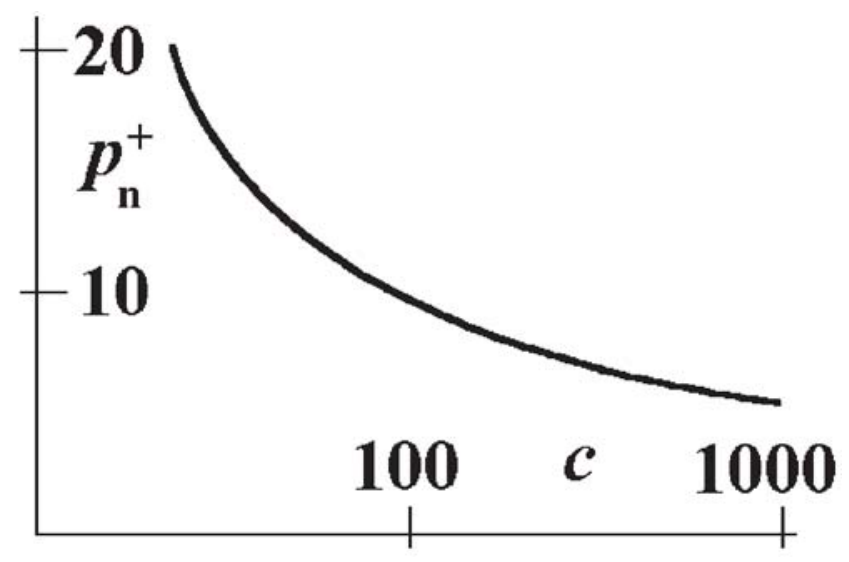

Fig. 12: Relation $p_{\mathrm{n}}^{+}$and $c$ for occurrence of bumps, fixed $\mathrm{E}$ and $\mathrm{G}$ of particles; the right hand side may be influenced by the boundary conditions (in the numerical model obvious cracking occurs, i.e., a drop in the stresses has to be expected).

The second example shows the influence of gas emission in the coal seam. The boundary of the gas blast is about $18 \mathrm{~m}$ from the face of opening. The effect of two magnitudes of the blast on the face stability is studied by the free hexagon method and then compared.

Figs. 15 and 17 show that $1 \mathrm{MPa}$ of gas causes local disturbances in the vicinity of the gas emission region, but that there is almost no influence on the face. More interesting is the case of magnitude $10 \mathrm{MPa}$. Fig. 16 shows that the most damaging blast causes even vertical disconnection in a large band in the upper part of the coal seam. This case can probably be estimated to be near the occurrence of the bumps.

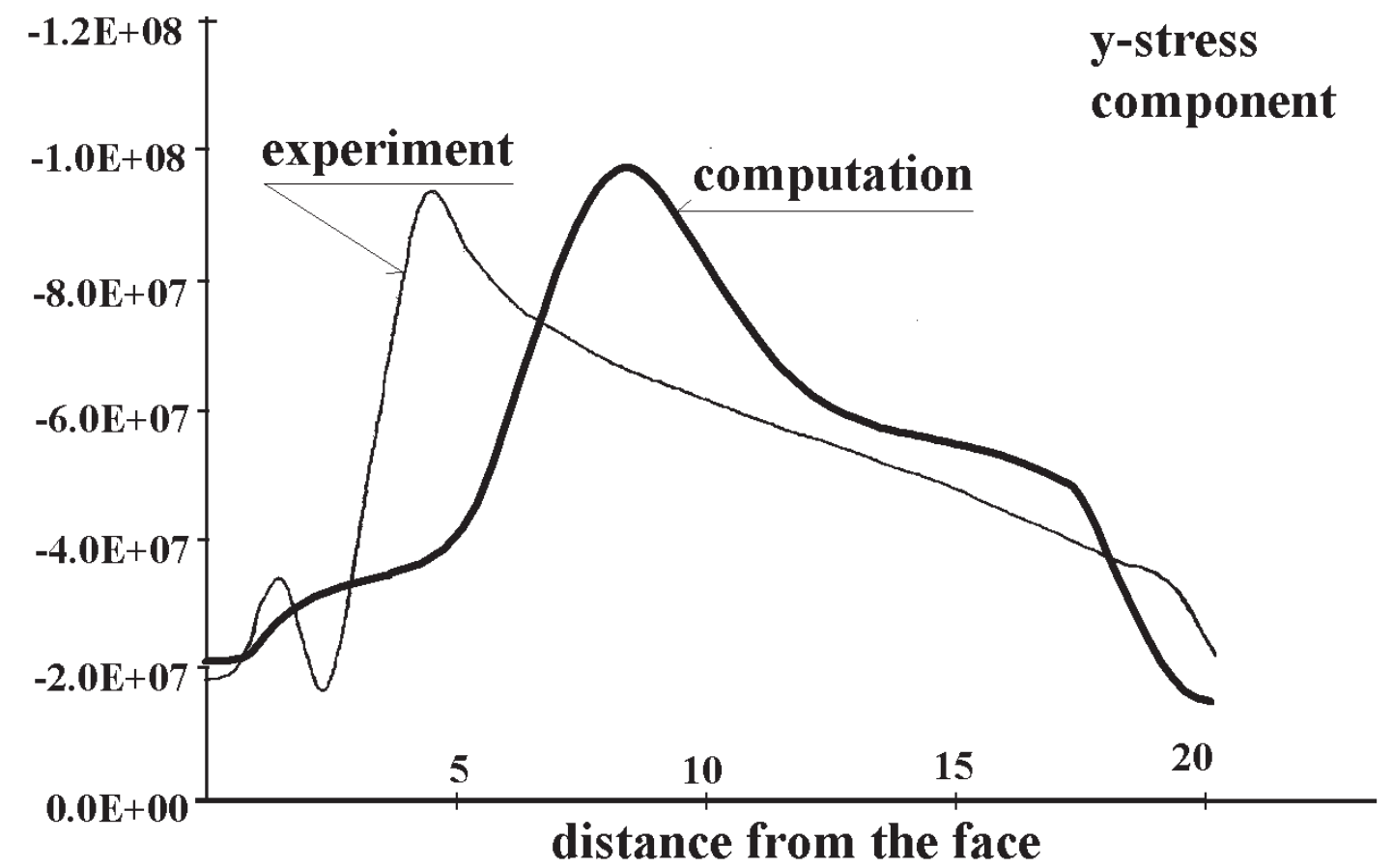

Fig. 13: Comparison experiment - computation for loading 2.5 MPa 


\section{loading}

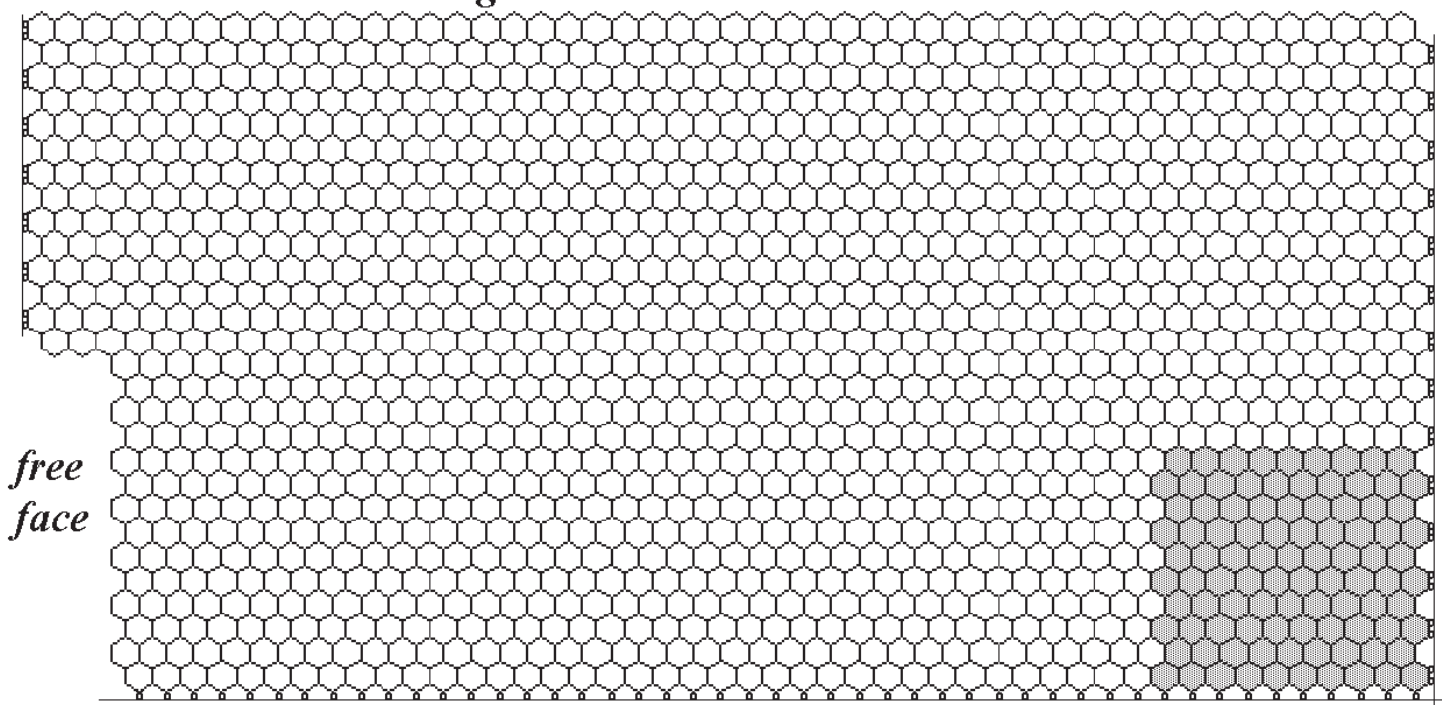

Fig. 14: Setting of the hexagonal elements and the domain of gas emission

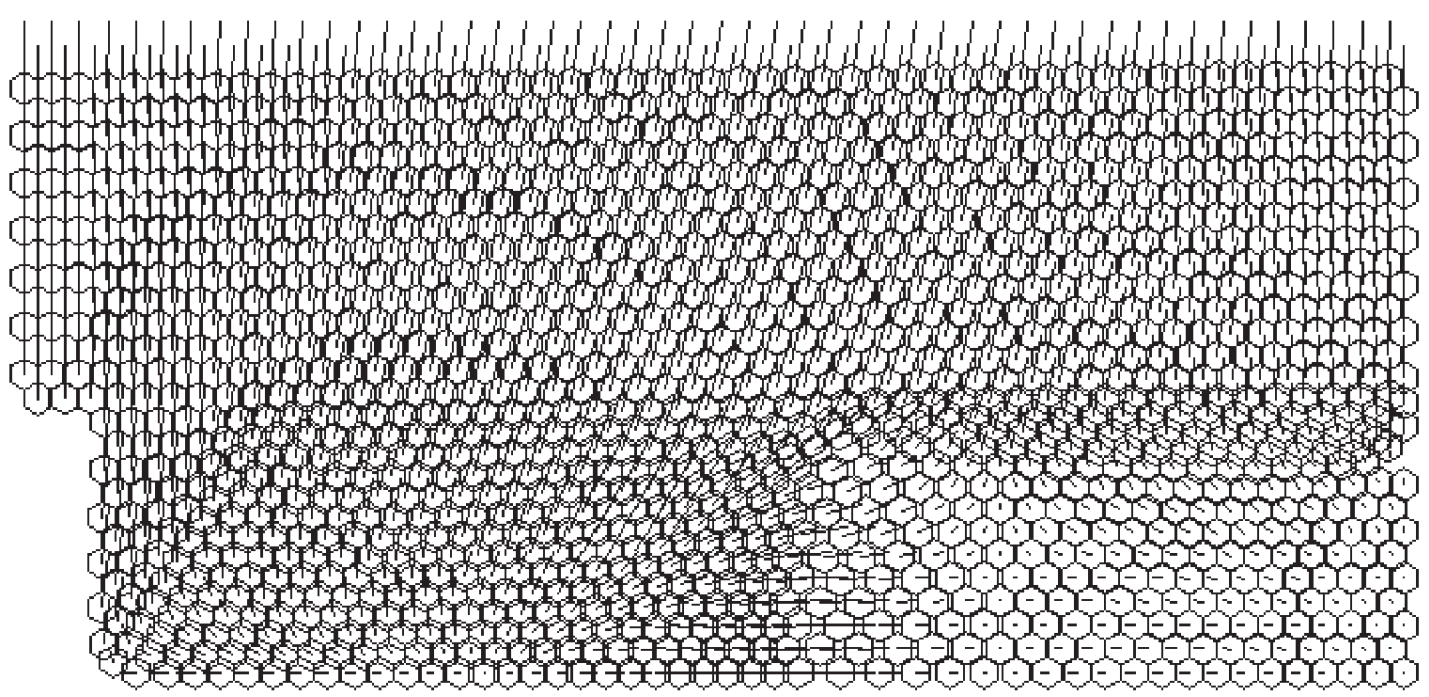

Fig. 15: Movements for $p_{\mathrm{n}}^{+}=10 \mathrm{kPa}, c=150 \mathrm{kPa}$, gas pressure $=1 \mathrm{MPa}$

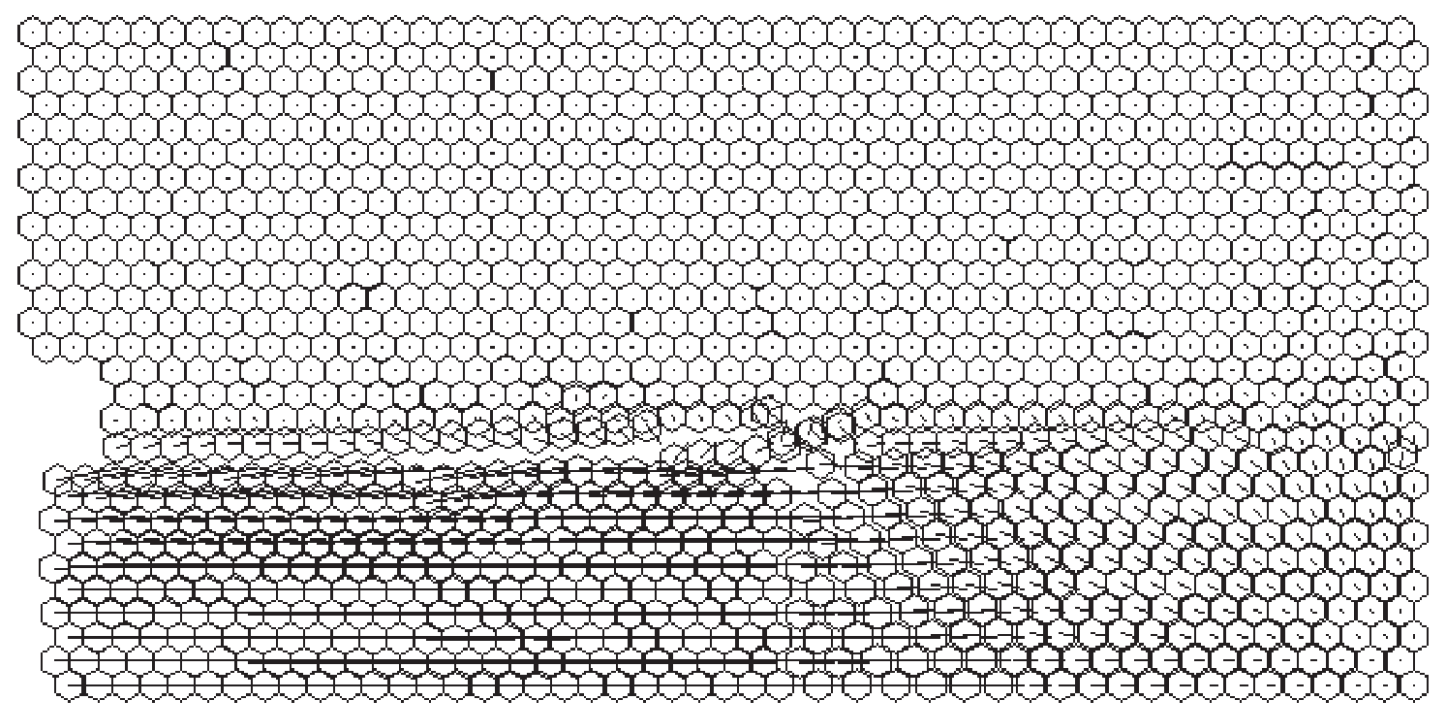

Fig. 16: Movements for $p_{\mathrm{n}}^{+}=10 \mathrm{kPa}, c=150 \mathrm{kPa}$, gas pressure $=10 \mathrm{MPa}$ 


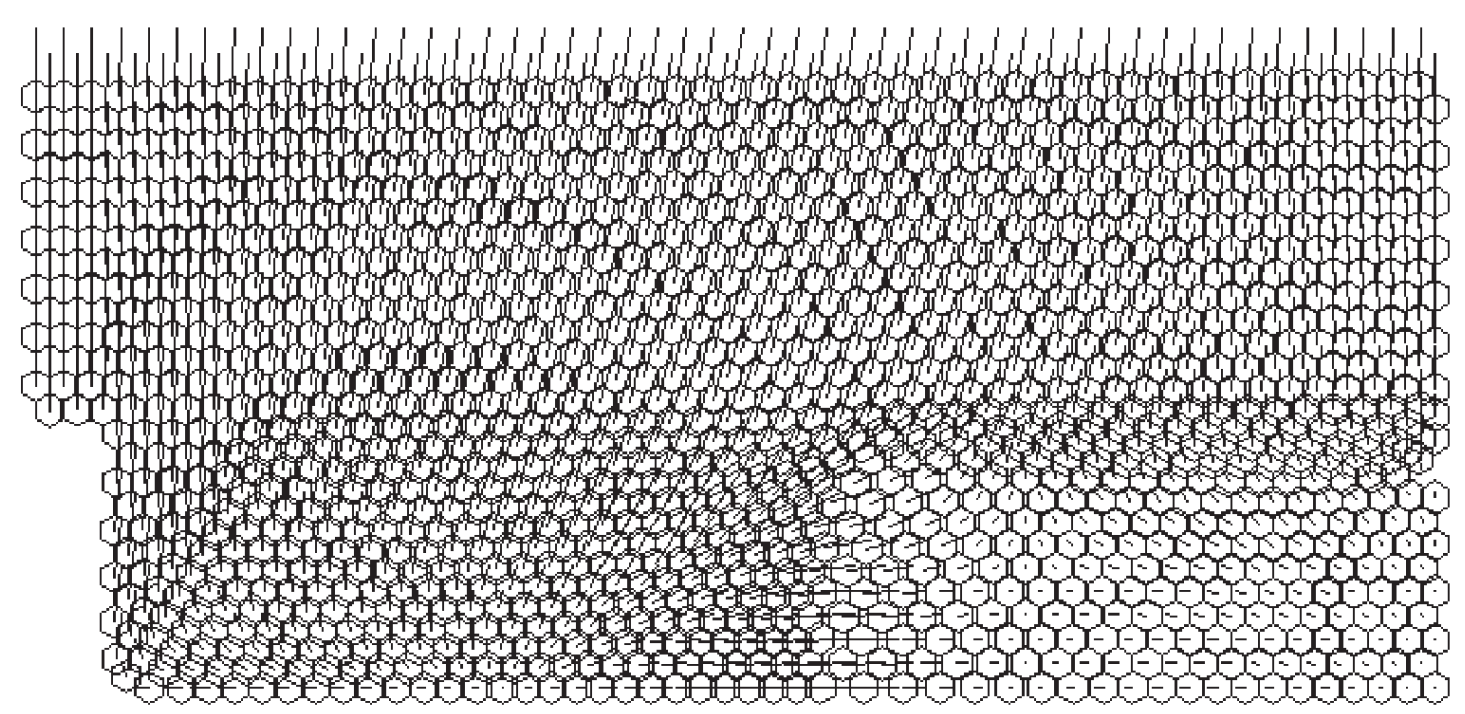

Fig. 17: Movements for $p_{\mathrm{n}}^{+}=10 \mathrm{kPa}, c=250 \mathrm{kPa}$, gas pressure $=1 \mathrm{MPa}$

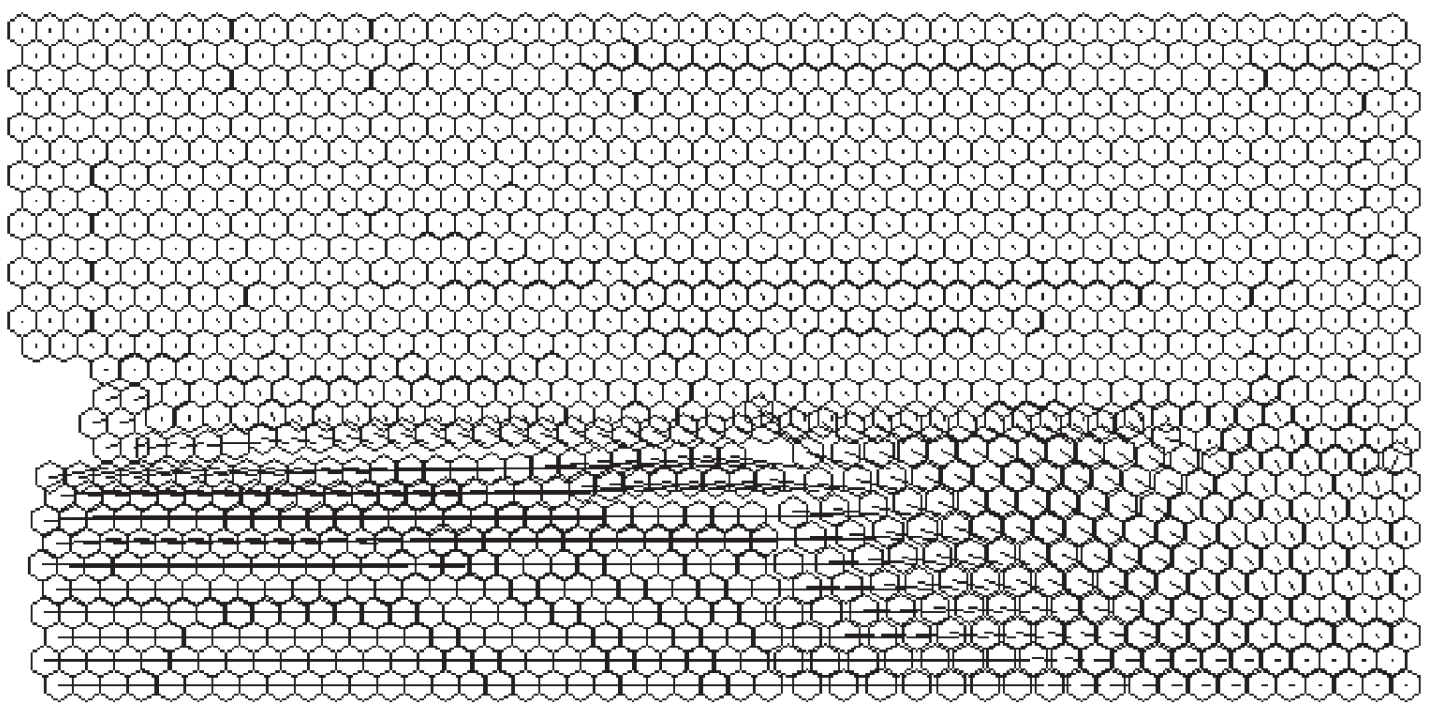

Fig. 18: Movements for $p_{\mathrm{n}}^{+}=10 \mathrm{kPa}, c=250 \mathrm{kPa}$, gas pressure $=10 \mathrm{MPa}$

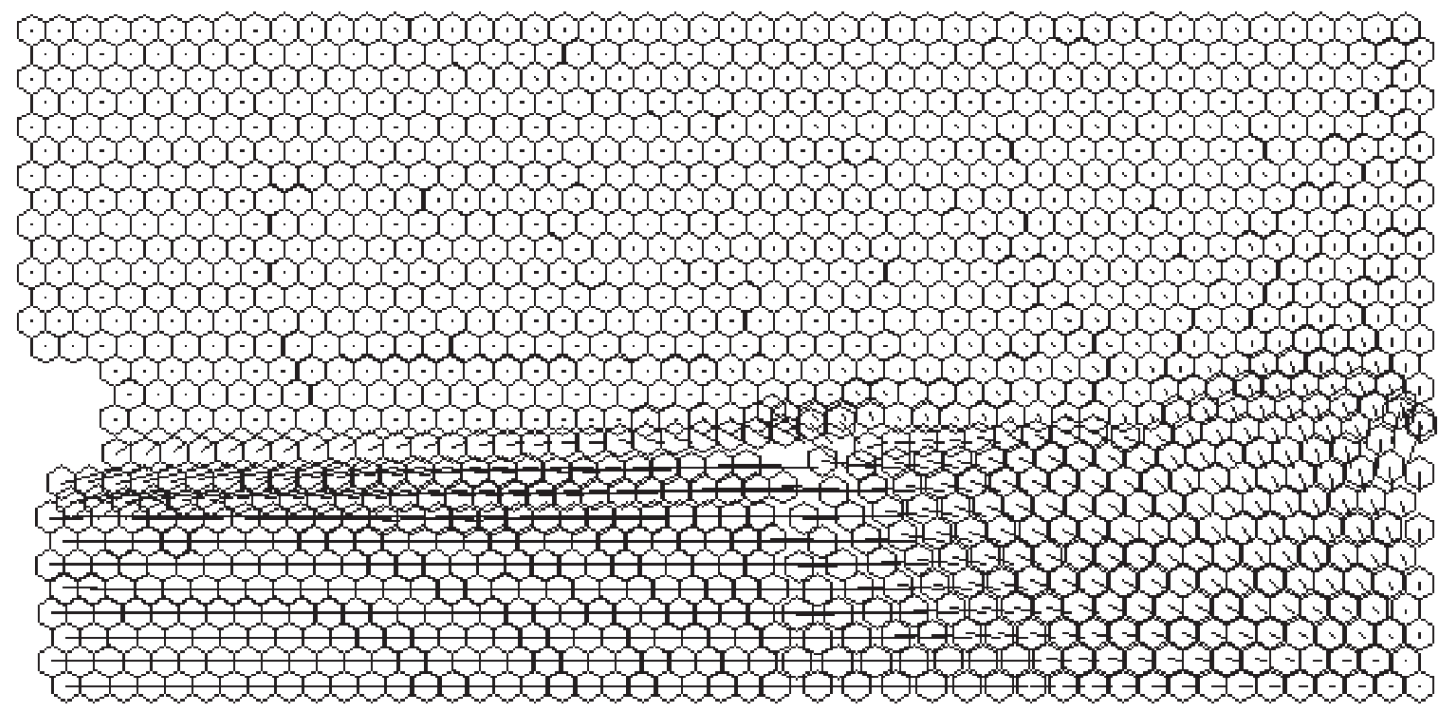

Fig. 19: Movements for $p_{\mathrm{n}}^{+}=25 \mathrm{kPa}, c=250 \mathrm{kPa}$, gas pressure $=10 \mathrm{MPa}$

(C) Czech Technical University Publishing House http://ctn.cvut.cz/ap/ 


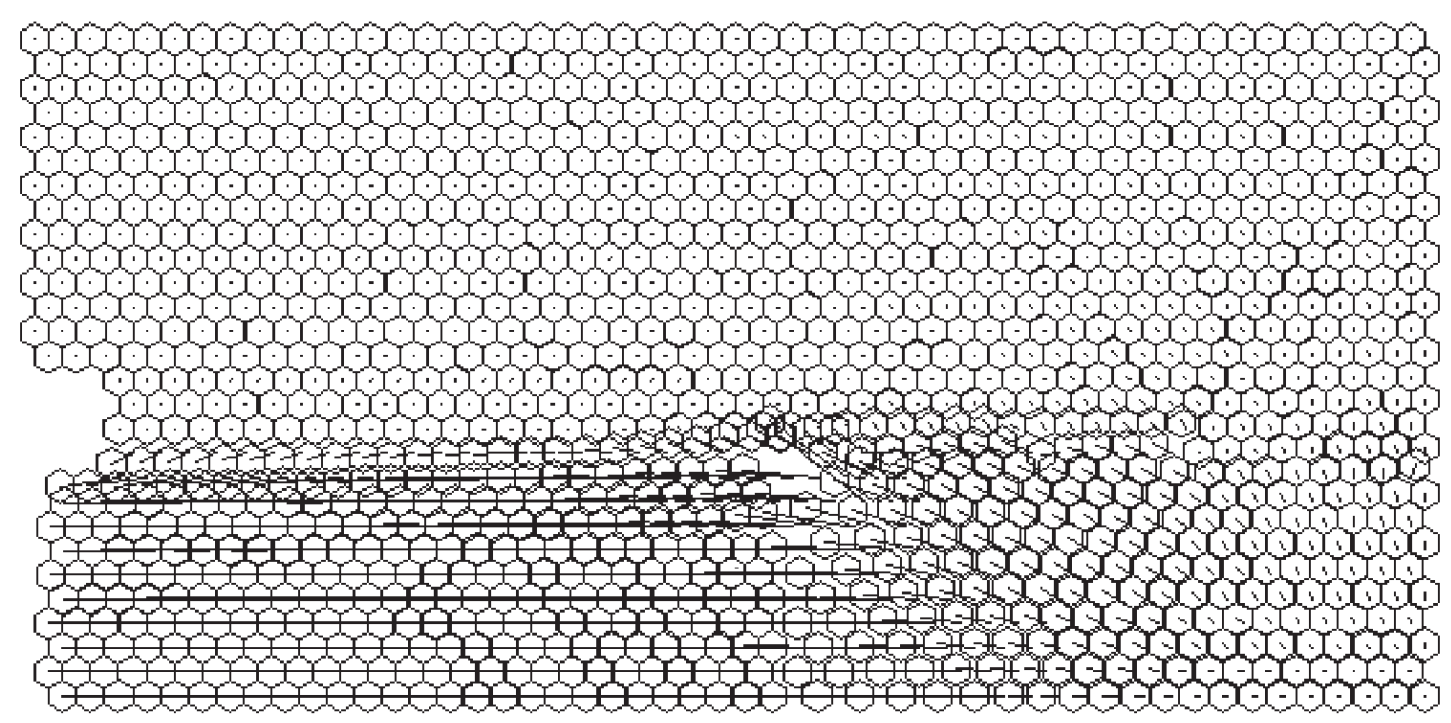

Fig. 20: Movements for $p_{\mathrm{n}}^{+}=40 \mathrm{kPa}, c=250 \mathrm{kPa}$, gas pressure $=10 \mathrm{MPa}$

The case described in Fig. 18 is also very dangerous. It is interesting that the "tensile band" has moved, and that the band is narrower. The stability of the face is still under threat. Figs. 19 and 20 show the influence of local "dilation" caused by the form of the particles. The displacements may be larger if the arrangement of the particles rotates by $90^{\circ}$.

\section{Conclusions}

This paper studies the behavior of open rock of the type that occurs during longwall mining in coalmines. The main problem is longwall instability and extrusion of the rock mass into an open space. This effect is mostly referred to as bumps or rock bursts. In order for bumps to occur, the rock has to possess certain special properties. In this study, we consider a brittle or almost brittle coal seam, which is treated theoretically, and experiments that have been carried out in the past are taken for comparison. The results from the two models seem to be reasonable. A combination of experimental and mathematical models appears promising for the study of similar problems. Both methods allow the problems to be studied as time dependent. They make it possible to develop cracks during bump initiation, and therefore describe the problem in a way that is very close to reality.

The free hexagonal element method (the principal method) is applied as a numerical tool, and the static particle flow code is a numerical method serving for comparison of the results from the two methods. The stiffness of the hexagons is created by the BEM. The generalized Hooke's law is used, involving eigenparameters, which can represent various material phenomena. Each element is considered to behave elastically (or rigidly in static PFC), and the contact conditions make the problem nonlinear. Using an iterative procedure, a very fast solution is obtained. If the solution converges, the process of deterioration of the coal seam and the rock mass can be observed and evaluated.

Two examples are presented. One starts with accumulation of energy due to external loading at a great depth in a mine, while the second example considers gas emission in the coal seam. The system of extrusion of coal particles describes the way they behave and the reasons, which locally affect the movements of the coal, or sometimes also the rock particles. The gas emission can be simulated by the eigenparameters, or by forces known as Eshelby's forces. In this paper Eshelby's forces are mainly used, although eigenparameters may also serve as an advantageous tool for simulating blasts.

As the process of cracking is influenced by contact conditions rather than by springs, static PFC is less reliable then the hexagon method. This assertion is verified by comparing the figures. Because of its simplicity in comparison to the free hexagonal element method, static PFC can be more applicable than hexagons in dynamic problems. Experience with classical PFC and its static version indicates that dynamic equilibrium applied to the static PFC concept is more reliable than classical PFC, where only a narrow range of material parameters delivers reasonable results. If we deviate from this range, the results are very unpredictable, and a concrete structure can burst out in space, for example.

\section{Acknowledgment}

This research was supported by Grant Agency of the Czech Republic - grant number 103/00/0530, and by Ministry of Education of the Czech Republic, project MSM:210000001,3.

\section{References}

[1] Brebbia, C. A., Telles, J. F. C., Wrobel, L. C.: Boundary Element Techniques. Berlin: Springer-Verlag, 1984.

[2] Cundall, P. A.: A computer model for simulation of progressive large scale movements of blocky rock systems. Symposium of the international society of rock mechanics, 1971, p. 132-150.

[3] Dvorak, G. J., Procházka, P. P.: Thick-walled Composite Cylinders with Optimal Fiber Prestress. Composites, Part B, Vol. 27B, 1996, p. 643-649.

[4] Eshelby, J. D.: The determination of the elastic field of an ellipsoidal inclusion, and related problems. JMPS Vol. 11, 1963, p. 376-396. 
[5] Haramy, K. Y., Morgan, T. A., De Waele, R. E.: A method for estimating western coal strengths from point load tests on irregular bumps. $2^{\text {nd }}$ Conf. on Ground Control in Mining, West Virginia University, July 19-21, 1982, p. 123-136.

[6] Haramy, K. Y., Magers, J. A., Mc Donnell, J. P.: Mining under strong roof. $7^{\text {th }}$ Int. Conf. on Ground Control in Mining, Denver (USA): Bureau of Mines, 1992, p. 179-194.

[7] Harami, K. Y., Brady, B. T.: A methodology to determine in situ rock mass failure. Internal report of Bureau of Mines, Denver (USA): CO, 1995.

[8] Kuch, R., Lippmann, H., Zhang, J.: Simulating coal mine bumps with model material. Gibowitz \& Lasocki (eds.), Balkema, Rotterdam: Rockbursts and seismicity in mines, 1997, p. 23-25.

[9] Procházka, P. P., Kugblenu, M.: Certain discrete element methods in problems of fracture mechanics problems. Acta Polytechnica, Vol 42, No. 4, p. 42-50.

[10] Procházka, P. P., Trčková, J.: Coupled modeling of concrete tunnel lining. Our World in Concrete and Structures, Singapore, (J. Tan ed.), 2000, p. 215-224.

[11] Silva, M. J., Gibson, L. J.: The effect of non-periodic microstructure and defects on the compressive strength of two-dimensional cellular solids. Int. J. of Mech. Sci. Vol. 39, No. 5, 1997, p. 549-563.
[12] Stilborg, B., Stephensson, O., Swan, G.: Three-dimensional physical model technology applicable to the scaling of underground structures. $40^{\text {th }}$ Int. Conf. on Rock Mech. Vol. 2, Montreux, 1979, p. 655-662.

[13] Ujihara, M., Higuchi, K., Nabeya, H.: Scale model studies and theoretical considerations on the mechanism of coal and gas outbursts. Int. Conf. OUTBURSTS, Sydney, 1986, p. 121-128.

[14] Vacek, J., Procházka, P. P.: Rock bumps occurrence during mining. CMEM, (C. A. Brebbia ed.), Alicante (Spain): 2001, p. 125-134.

Prof. Ing. RNDr. Petr P. Procházka, DrSc.

phone: +420224354480

fax: +420224310775

e-mail: petrp@fsv.cvut.cz

Ing. Michael G. Kugblenu

Dept. of Structural Mechanics

CTU in Prague

Faculty of Civil Engineering

Thákurova 7

16629 Prague 6, Czech Republic 